\title{
EFFECT OF CEC OF CLAY ON THERMAL CONDUCTIVITY
}

\author{
James Adeyemo Adegoke', Godwin Egbeyale ${ }^{1,2}$ and Olukayode Akinyemi ${ }^{3}$ \\ ${ }^{1}$ Department of Physics, University of Ibadan, Ibadan, Nigeria. \\ ${ }^{2}$ Department of Physics, Kwara State University, Ilorin, Nigeria. \\ ${ }^{3}$ Department of Physics, Federal University of Agriculture, Abeokuta, Nigeria. \\ e-mail:godwinegbeyale@gmail.com, adegokeja@yahoo.com \\ Received: 25 May 2016 Accepted: 24 Dec 2016
}

\begin{abstract}
The thermal conductivity of clay doped with different concentrations of nitrate of heavy metals is presented in this study. Clay sample from Omi Adio, Ibadan, Southwestern part of Nigeria was used to investigate this work. Cation exchange, which occurs naturally with soil water, was the method explored to carry out the investigation. A microprocessor-based thermal analyzer was used to determine the thermal conductivity while Atomic absorption spectrophotometer was used to determine the heavy metal concentration. $52.0 \mathrm{~g}$ clay sample was mixed with $70 \mathrm{~cm}^{3}$ of nitrate of $\mathrm{Pb}$ (II), Cd (II), $\mathrm{Zn}$ (II), $\mathrm{Cr}$ (II), Fe (II), $\mathrm{Hg}$ (II), $\mathrm{Cu}$ (II), and Ni (II) solutions at different concentrations; after which slabs of dimensions $4 \mathrm{~cm}$ x $4 \mathrm{~cm}$ x $1 \mathrm{~cm}$ were made from the mixture of the clay sample with aqueous solutions of different concentrations and the thermal conductivities determined. Thermal conductivity values were plotted against concentration of nitrate of heavy metals; $400 \mathrm{ppm}, 800 \mathrm{ppm}, 1600 \mathrm{ppm}$, $3200 \mathrm{ppm}$ and $6400 \mathrm{ppm}$. Results showed that thermal conductivity of clay increases with increase in the concentration of heavy metal adsorbed by the clay to an optimum level. The lowest thermal conductivity was found to be $0.06 \mathrm{~W} / \mathrm{mK}$ (for control clay) and the highest was found to be $0.38 \mathrm{~W} / \mathrm{mK}$ (at $6400 \mathrm{ppm}$, Copper). For all the samples, thermal conductivity increases as the concentration of heavy metals increases to a certain optimum level above which cation exchange is no longer possible. From the results, it was concluded that the increase of concentration of heavy metals adsorbed by clay during cation exchange process contributes to its thermal conductivity.
\end{abstract}

Keywords: Adsorption, Clay, Concentration, Thermal conductivity, Heavy metals

\section{INTRODUCTION}

Heat is a form of energy and regarded as a process of transfer from one place to another through a conductor as a result of a temperature different between its ends. It can be stored by all kinds of materials. Some materials have ability to store large quantity (good conductor) of heat while others at small quantity (poor conductor). Materials such as rocks, soil, metals etc conduct heat easily. Soil is the most common product of weathering and formed by the decomposition and disintegration of rocks. The thermal properties of soil are a component of soil physics that has found important uses in climatology, engineering and agriculture. These properties influence how energy is partitioned in the soil profile. While related to soil temperature, it is more accurately associated with the transfer of heat throughout the soil, by radiation, conduction and convection.

Clay is defined as a natural, earthy, fine grained material which develops plasticity when mixed with a limited amount of water, composed primarily of silica, alumina and water, etc [20]. It is characterized from other small particle present in the soil by their small particle size which is less than $2 \mu \mathrm{m}$ in diameter, affinity for water, high plasticity index, cation exchange capacity, chemical and mineral content. However, clay may contain heavy metals depending on the prevailing geologic minerals. Heavy metals are a group of elements on the periodic table of elements, having specific gravities greater than 4.0 [1].

Clays are of immense geological, industrial and agricultural importance [14][6]. The 
mineral assemblage of clays helps in understanding and management of erosion and flood related problems [13], and in the construction of tunnels, road cuts, fills and dams [16]. Depending on the physical and chemical characteristics, clays may find application in a number of industries such as paint, plastics, ceramics, pharmaceutical, ink, catalysts, and fibre glass among others [22][14][7].

The physical, chemical and mineralogical characteristics of Odukpani clay deposits and their brick forming properties have been reported [3][16]. The results obtained for these deposits and those from Calabar, Cross River state, Nigeria revealed that their properties are useful for several applications [3].

Knowledge of soil thermal properties is an important factor in understanding mass and energy exchange processes in the soil atmosphere [18]. The chemical composition of soils will therefore indirectly relate to their thermal conductivities. Thermal conductivity of a material is an important engineering property which is related to heat transfer characteristics. This parameter is essential in studying heating, drying and cooling processes for crop (seeds) and building materials. Thermal properties of many materials have been reported in the literature, and most of these data are compiled by Polley [17] and ASAE [2] for engineering research and design purposes. Soil thermal properties have direct influence on seed germination, seedling emergence and subsequent crop growth [9]. According to Usowicz [21], this knowledge can also help in controlling the thermal-moisture regime of soils. Soil properties often correlate with metal adsorption which include soil $\mathrm{pH}$ [5][11], soil CEC (cation exchange capacity) [10][19], soil organic matter [8][24], and clay content [12]. Though, clays are regarded as low thermal conductor, additive agents on clay has not received good attention. In addition, the functional relationship between thermal conductivity and the heavy metal contents has not received attention. This study therefore aimed at investigating the variation of thermal conduction of clay with adsorption optimization.

\section{THEORETICAL BACKGROUND}

In an isotropic medium, $k$ is the thermal conductivity in the Fourier expression for the heat flux

$$
H=\frac{Q}{t}=-k A \frac{d T}{d x}
$$

$A$ is the total cross-sectional area of conducting surface, $d T$ is the temperature difference and $d x$ is the thickness of the conducting surface separating the two temperatures.

Hence;

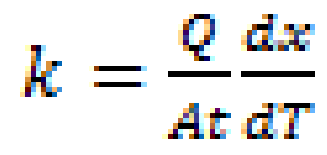

$Q$ is the quantity of heat energy conducted per unit time, and $t$ is time taken to conduct heat energy through $d x$.

\section{MATERIALS AND METHODS}

Clay sample used in this study was sourced from Bricks and Clay product, Omi- Adio, Ibadan, in the south western part of Nigeria. It is located on Longitude $3^{0} 30^{1}$ and Latitude $7^{\mathrm{o}} 32^{1}$.

The clay sample collected was crushed with pestle and mortar and sieved. The sieved 
sample was put into polythene bag. The crushing and sieving were done in order to make the sample homogenous and fit for the experimental work.

Sample was digested by using Nitric acid extraction method. The sample was first digested to know the initial concentration of heavy metal present in it.

\subsection{Experimental procedure for digested sample}

Nitric acid extraction method involves digestion of sample in a mixture of $\mathrm{HNO}_{3}$, $\mathrm{HF}$ and $\mathrm{HClO}_{4}$, Nitric acid, Hydrofluoric acid and Perchloric acid, respectively.

One gram of each of the samples was weighed into a Teflon beaker while $10 \mathrm{ml}$ of concentrated nitric acid $\left(\mathrm{HNO}_{3}\right)$ was added and heated. About $70 \%$ of the mixture was allowed to dry off and $10 \mathrm{ml}$ of hydrofluoric acid (HF) was added to the mixture, followed by evaporation to about $20 \%$ total volume. After $5 \mathrm{ml}$ of perchloric acid $\left(\mathrm{HClO}_{4}\right)$ was added, the whole mixture was allowed to dry by evaporation. One millilitre nitric acid was added to dissolve the residue and about $10 \mathrm{ml}$ distilled water was added and allowed to boil and later transferred to a $25 \mathrm{ml}$ standard flask filled to the mark with deionised water.

\subsection{Experimental Analysis of digested samples}

The digested samples were taken for heavy metal analysis using Atomic absorption Spectrophotometer. Samples were analyzed for the following metals; Lead $(\mathrm{Pb})$, Chromium (Cr), Nickel (Ni), Cadmium $(\mathrm{Cd})$, Manganese $(\mathrm{Mn})$, Copper $(\mathrm{Cu})$ and Zinc (Zn) (Table1). The concentration of these heavy metals in the clay sample were obtained in part per million (ppm) from the machine. Second elemental analysis was done on the sample after nitrate of heavy metals had been added.

\subsection{Preparation of Nitrate of Heavy Metals Stock Solutions}

The concentrations of nitrate of heavy metals needed for this work were prepared from stock solution using dilution method. 6400 ppm of Lead, Zinc, Cromium, Iron, Mercury, Cadmium, Nickel, and Copper nitrate solution were prepared as the stock solution. Concentration of heavy metal nitrate solutions prepared was $400 \mathrm{ppm}, 800$ ppm, 1600 ppm, 3200 ppm and 6400 ppm.

$10.23 \mathrm{~g}$, of $\mathrm{Pb}\left(\mathrm{NO}_{3}\right)_{2}$ salt that contained 6.4 $\mathrm{g}$ of $\mathrm{Pb}$ was weighed and transferred quantitatively to one litre standard flask. Deionized water was then poured into the flask up to the mark. This concentration was 6400 ppm stock solution. The method of preparation of this stock solution was based on mass - volume relationship.

\subsection{Formation of slabs from clay sample:}

Dry clay sample of mass $52.0 \mathrm{~g}$ (volume, 43 $\mathrm{cm}^{3}$ ) was put in the beaker. Nitrate of prepared lead solution $70 \mathrm{~cm}^{3}$, was added to the measured powder clay. The solute (powder clay) and solvent (lead nitrate solution) were mixed together with the help of stirrer. Some minute later, the mixture was gently poured into a funnel containing filter paper and was left for two days under unpolluted condition, to avoid contamination. Thereafter, the residue was placed and dressed in a clean frame of dimension $4 \mathrm{~cm} \times 4 \mathrm{~cm} \times 1 \mathrm{~cm}$. After two days, the slab was taken out of the frame and sun-dried in a pollution free environment. The procedure was repeated for different concentration of nitrate of heavy metals at 400 ppm, 800 ppm 1600 ppm, 3200 ppm and $6400 \mathrm{ppm}$. After sun-drying, samples were oven dried. 


\subsection{Measurement of thermal conductivity}

The thermal conductivities measurements were carried out using a KD2 thermal property analyzer. KD2 thermal property analyzer is an instrument that measure thermal conductivity, thermal diffusivity and temperature. It is a compact portable meter consisting of a hand held read-out unit and a $6 \mathrm{~cm}$ single needle sensor with diameter of $0.9 \mathrm{~mm}$ that can be inserted into the medium under investigation. The theory is based on the assumption that the heat source placed in an isotropic and homogenous medium is infinitely long under a uniform initial temperature.

The controller of the KD2 thermal property analyzer was first precondition for about 60s. The reason for this is to allow the instrument to attain the operational temperature and heats the probe for effective measurement of thermal conductivity. The heating process enables the controller to compute the thermal conductivity of the sample.

The governing equation according to Carslaw and Jaeger [4] is: $\frac{\partial T}{\partial t}=\alpha\left\{\frac{\partial^{2} T}{\partial r^{2}}+r^{-1} \frac{\partial T}{\partial r}\right\}$,

where $r$ is the radial distance $(\mathrm{m}), T$ is the temperature $\left({ }^{\circ} \mathrm{C}\right), \alpha$ is the thermal diffusivity $\left(\mathrm{m}^{2} / \mathrm{s}\right)$, and $t$ is the time (s).

\section{RESULTS AND DISCUSSIONS}

The clay soil sample collected from Omi adio, Ibadan, Ido local government was used to form slabs of different concentration of nitrate of heavy metals as shown on Table1 Table3. After oven-dried, their thermal conductivities were determined, using KD2 thermal analyzer and are presented on Table 1. Before the introduction of different nitrate of heavy metals thermal conductivity of this sample was $0.06 \mathrm{~W}(\mathrm{mK})^{-1}$. In this study, the thermal conductivity of clay increased with an increase in the amount of nitrate of heavy metals solution. The results of this work are presented in tabular form. Table 1 shows the thermal conductivity and different concentration of heavy metals, Table 2 shows the concentration of heavy metals in the filtrate and Table 3 shows the concentration of heavy metals retained in the sample

Table 1: Thermal conductivity and concentration of nitrate of heavy meatals.

\begin{tabular}{llllllllll}
\hline \multirow{2}{*}{$\begin{array}{l}\text { CONCENTRATION } \\
\text { (PPM) }\end{array}$} & \multicolumn{1}{l}{ THERMAL CONDUCTIVITY, $\mathrm{k}(\mathrm{W} / \mathrm{mK})$} \\
\cline { 2 - 11 } & $\mathrm{BP}$ & $\mathrm{Cu}$ & $\mathrm{Cd}$ & $\mathrm{Cr}$ & $\mathrm{Ni}$ & $\mathrm{Hg}$ & $\mathrm{Zn}$ & $\mathrm{Al}$ & $\mathrm{Fe}$ \\
\hline 400 & 0.06 & 0.16 & 0.09 & 0.10 & 0.09 & 0.06 & 0.10 & 0.11 & 0.09 \\
800 & 0.11 & 0.24 & 0.12 & 0.12 & 0.11 & 0.09 & 0.13 & 0.13 & 0.11 \\
1600 & 0.13 & 0.27 & 0.14 & 0.14 & 0.13 & 0.10 & 0.14 & 0.16 & 0.12 \\
3200 & 0.16 & 0.32 & 0.14 & 0.15 & 0.14 & 0.10 & 0.15 & 0.19 & 0.20 \\
6400 & 0.17 & 0.38 & 0.14 & 0.16 & 0.14 & 0.11 & 0.16 & 0.23 & 0.22 \\
\hline
\end{tabular}


Table 2: Concentration ( in ppm) of heavy metals in the filtrate after adsorption process.

\begin{tabular}{lllllll}
\hline $\begin{array}{l}\text { Concentration } \\
\text { Used } \\
\text { ppm }\end{array}$ & $\begin{array}{l}\text { Lead } \\
(\mathrm{Pb})\end{array}$ & $\begin{array}{l}\text { Copper } \\
(\mathrm{Cu}) \mathrm{ppm}\end{array}$ & $\begin{array}{l}\text { Cadmium } \\
(\mathrm{Cd}) \mathrm{ppm}\end{array}$ & $\begin{array}{l}\text { Chromium } \\
\mathrm{Cr}) \\
\mathrm{ppm}\end{array}$ & $\begin{array}{l}\text { Nickel } \\
(\mathrm{Ni}) \mathrm{ppm}\end{array}$ & $\begin{array}{l}\text { Zinc } \\
(\mathrm{Zn}) \\
\mathrm{ppm}\end{array}$ \\
\hline 400 & 0.93 & 0.25 & 0.14 & 0.29 & 0.27 & 0.11 \\
800 & 1.28 & 0.28 & 0.09 & 0.46 & 0.49 & 0.21 \\
1600 & 1.47 & 0.29 & 0.21 & 0.63 & 0.58 & 0.62 \\
3200 & 2.08 & 0.33 & 1501.52 & 0.64 & 0.74 & 0.84 \\
6400 & 2761.28 & 1000.33 & 4700.36 & 2000.82 & 3000.81 & 2000.89 \\
\hline
\end{tabular}

Table 3: The amount of concentration remained on the clay sample as a result of cation exchange of heavy metal that had taken place.

\begin{tabular}{lllllll}
\hline $\begin{array}{l}\text { Concentration } \\
\text { Used } \\
\text { ppm }\end{array}$ & $\begin{array}{l}\text { Lead(Pb) } \\
\text { ppm }\end{array}$ & $\begin{array}{l}\text { Copper } \\
(\mathrm{Cu}) \\
\mathrm{ppm}\end{array}$ & $\begin{array}{l}\text { Cadmium } \\
(\mathrm{Cd}) \mathrm{ppm}\end{array}$ & $\begin{array}{l}\text { Chromium } \\
\mathrm{Cr}) \mathrm{ppm}\end{array}$ & $\begin{array}{l}\text { Nickel } \\
(\mathrm{Ni}) \mathrm{ppm}\end{array}$ & $\begin{array}{l}\text { Zinc } \\
(\mathrm{Zn}) \\
\mathrm{ppm}\end{array}$ \\
\hline 400 & 399.81 & 402.63 & 400.00 & 402.56 & 401.49 & 408.38 \\
800 & 799.46 & 802.60 & 800.05 & 802.39 & 801.32 & 808.28 \\
1600 & 1599.25 & 1602.60 & 1599.93 & 1602.22 & 1601.18 & 1607.87 \\
3200 & 3198.66 & 3202.55 & 1698.32 & 3202.21 & 3201.02 & 3207.65 \\
6400 & 3639.45 & 5402.55 & 1699.78 & 4402.03 & 3400.95 & 4407.60 \\
\hline
\end{tabular}

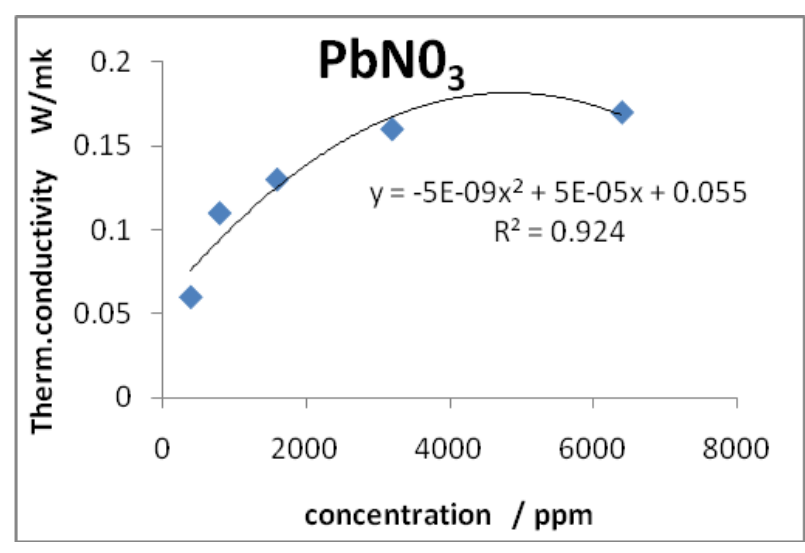

Figure 1: Graph of thermal conductivity against concentration of lead nitrate.

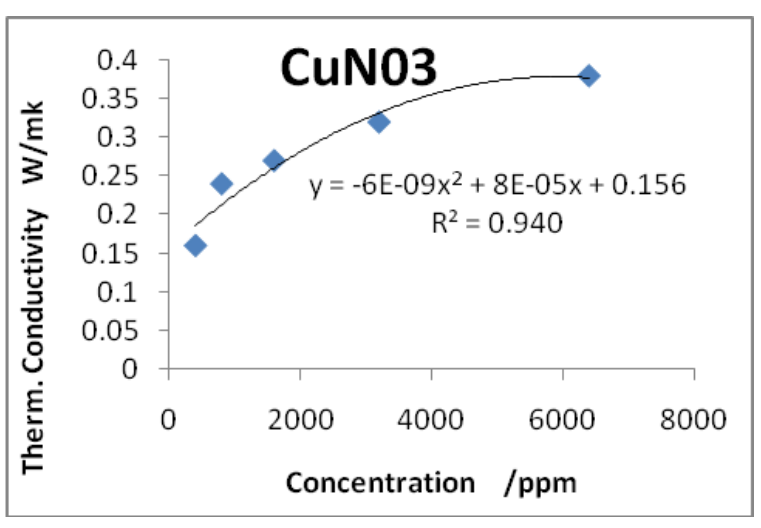

Figure 2: Graph of thermal conductivity against concentration of Copper nitrate. 


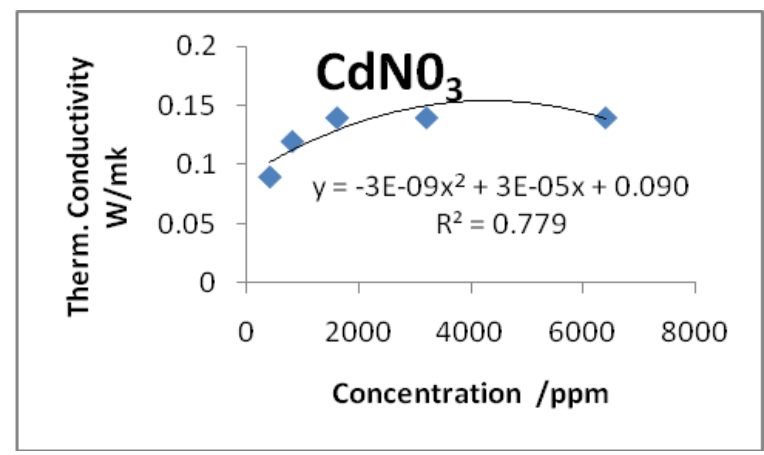

Figure 3: Graph of thermal conductivity against concentration of cadmium nitrate.

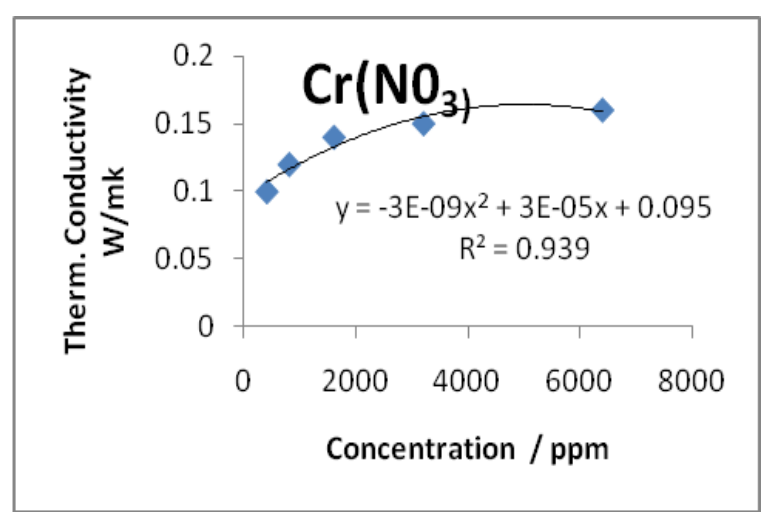

Figure 4: Graph of thermal conductivity against concentration of Chromium nitrate.

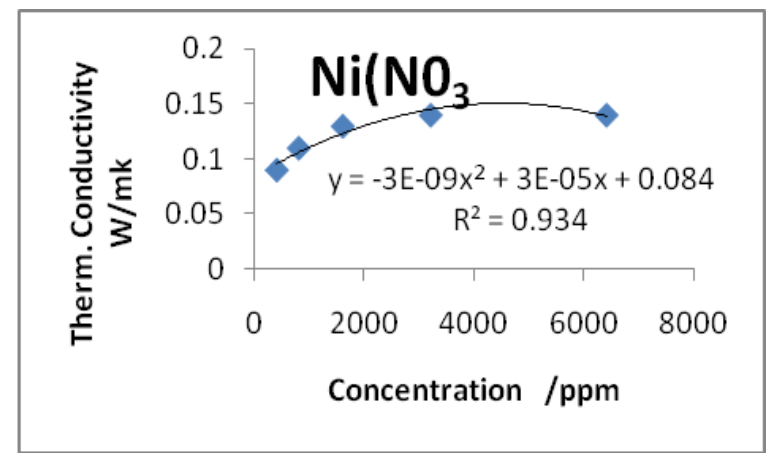

Figure 5: Graph of thermal conductivity against concentration of Nickel nitrate.

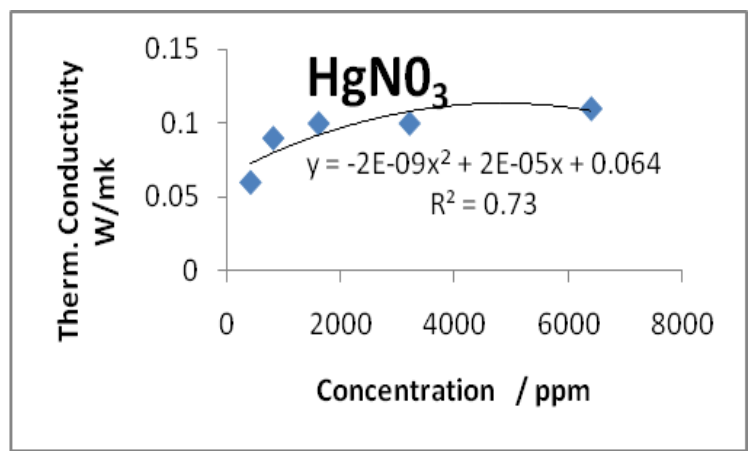

Figure 6: Graph of thermal conductivity against concentration of mercury nitrate.

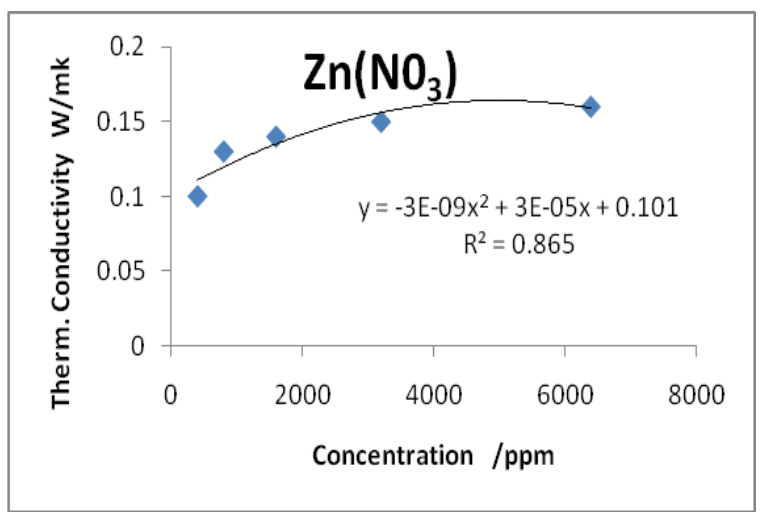

Figure 7: Graph of thermal conductivity against concentration of Zinc nitrate.

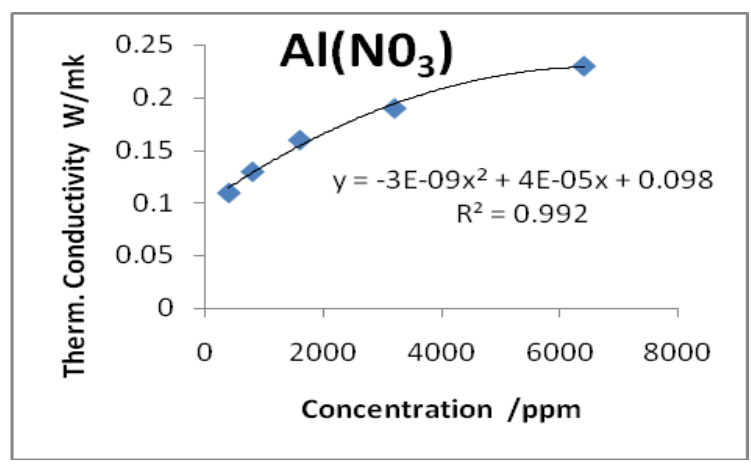

Figure 8: Graph of thermal conductivity against concentration of Aluminium nitrate. 


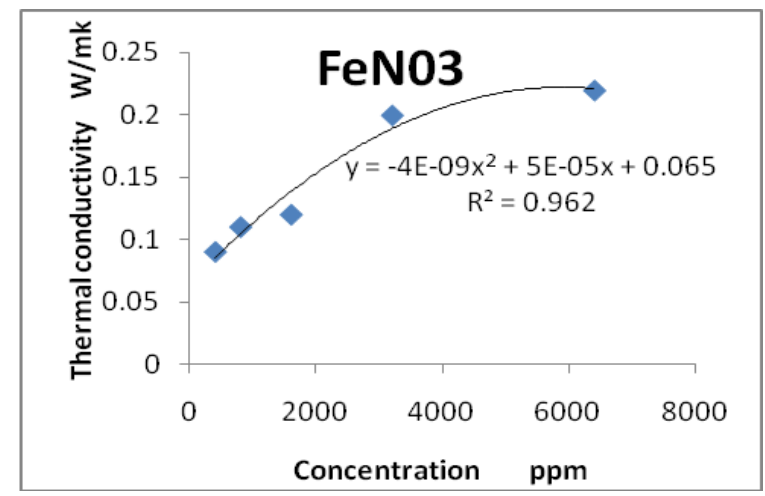

Figure 9: Graph of thermal conductivity against concentration of Iron nitrate.

\subsection{Effect of concentration on thermal conductivity}

Table 1 and Figure1-9 showed that the thermal conductivity of clay increases with increase in the concentration of heavy metal adsorbed by the clay. It increases to a certain level (optimum) above which cation exchange is no longer possible due to inability to adsorp more ions. Sample containing solution of Cadmium ion reached its peak value before others. Its optimum (peak) value was reached when the concentration of Cadmium was 1600 ppm and it remains constant as the concentration increases. This was due to its saturation level and at this point it can no longer adsorb cadmium again. So, beyond $1600 \mathrm{ppm}$ concentration there is constant in thermal conductivity.

Others showed rapid increase of thermal conductivity at low concentration of heavy metals ions and at high concentration, there was gradual increase. Later thermal conductivity of mercury and Nickel nitrate solution ion remains constant at $1600 \mathrm{ppm}$ to 6400ppm while Lead, Iron, Chromium, Zinc and Aluminium showed slight increase. Clays doped with Cadmium nitrate reached its thermal equilibrium/optimum at 1600 ppm while Nickel at 3200 ppm others still increase as their concentration increases.
This means that clay sample doped with aluminium can still take more ions in as much saturation has not reached.

These results above are useful information for soil scientist, agriculturist and engineers. Since thermal conductivity performance is an important criterion of building materials because the thermal conductivity influences the selection of building materials in engineering application [23]. In soil science, it has direct influence on seed germination and crop growth [9]. If the concentration of these heavy metals increases in the soil it will lead to increase in the rate of heat conduction as temperature changes.

\subsection{Effect of Cation exchange on thermal conductivity}

The negative charges of clay are neutralizes by a swarm of positive charged ions (cation). These cations, which are held electrostaticaly on the surface of the soil, are called adsorbed cations. Adsorbed cations can be replaced or exchange by other cations from the soil solution. The process of replacement is known as cation exchange. This process of cation exchange was explored in this work and deduces that thermal conductivity of clay sample increase as the concentration of cation attached at the surface of clay increases. 
Thermal conductivity of clay doped with lead nitrate ranges from $0.09 \mathrm{~W} / \mathrm{mk}$ at 400 $\mathrm{ppm}$ to $0.22 \mathrm{~W} / \mathrm{mk}$ at $6400 \mathrm{ppm}$. Samples with Mercury nitrate solution has thermal conductivity range from $0.06 \mathrm{~W} / \mathrm{mk}$ to $0.11 \mathrm{~W} / \mathrm{mk}$. Similarly, samples with copper nitrate solution has $0.16 \mathrm{~W} / \mathrm{mk}$ to $0.38 \mathrm{~W} / \mathrm{mk}$, Iron nitrate solution $(0.09-0.22 \mathrm{~W} / \mathrm{mk})$, Cadmium nitrate solution (0.09 - 0.14 $\mathrm{W} / \mathrm{mk})$, Chromium nitrate solution $(0.10-$ $0.16 \mathrm{~W} / \mathrm{mk})$, Nickel nitrate solution $(0.09-$ $0.14 \mathrm{~W} / \mathrm{mk})$, Zinc nitrate solution $(0.10-$ $0.18 \mathrm{~W} / \mathrm{mk}$ ), Aluminium nitrate solution $(0.11-0.23 \mathrm{~W} / \mathrm{mk})$,

From the graph, we deduce that thermal conductivity increases sharply with increase in concentration when the ions in the sample have not reached saturated value and gradually when the ions in the sample approaches or are close to saturation point.

The results showed that the thermal conductivity of clay increases up to a point as the concentration of heavy metal increases. In fact, observation shows that thermal conductivity of clay depends majorly on the elemental composition of the clay concerned and the strength of adsorption rate of clay. At $400 \mathrm{ppm}$ up to $6400 \mathrm{ppm}$, clay reached in copper has the highest thermal conductivity followed by clay reached in Iron, Zinc and next by Lead. The implication of this is that soil reached in copper will conduct more heat than other metals, even if the concentrations of other heavy metals in soil are more than the concentration of copper.

\section{CONCLUSION}

The thermal conductivity of clay was measured using the heat wire (KD2 thermal analyzer) method. According to this research, thermal conductivity of clay increases as the adsorption of heavy metal increases. This means that cation exchange influenced the heat conduction of clay doped with different concentration of heavy metals. The study also discovered that elemental composition of the material contributed to the rate at which heat was conducted through it. In other words, thermal conductivity of clay can be influenced by cation exchange capacity and elemental composition of the material. Thermal conductivity of clay can be increased by adsorption of heavy metals and cation exchange process. Results obtained showed that thermal conductivity of clay increases with increase in the concentration of heavy metal adsorbed by the clay to a point where saturation occurs and beyond this point exchange of cation is not possible. The lowest thermal conductivity was found to be $0.06 \mathrm{~W} / \mathrm{mK}$ (for control clay) and the highest was found to be $0.38 \mathrm{~W} / \mathrm{mK}$ (at $6400 \mathrm{ppm}$, Copper). For all the samples, thermal conductivity increases as the concentration of heavy metals increases to a certain optimum level above which cation exchange is no longer possible. It was therefore concluded that the increase of concentration of heavy metals adsorbed by clay during cation exchange process caused variation in thermal conductivity. That is, the cation exchange capacity of clay has great effect on thermal conductivity of any material.

\section{ACKNOWLEDGEMENTS}

The authors appreciate the effort of the following people in Federal university of Agriculture, Abeokuta, Physics laboratory; Prof. Akinyemi, Mr. Najim, Mr. Y. Maculy and Mr. Kuforiji for the thermal conductivity measurements. They also thank Mr. Wilhem, who gave us permission to use the AAS (Atomic Absorption Spectrophotometer, Buck Scientific Model 210VGP) in the Department of Agronomy, university of Ibadan for heavy metal determination. 


\section{REFERENCES}

1. Adriano, D.C. (1986). Trace Elements in the Terrestrial Environment. New York, NY. Springer - Verlag: Berlin, Germany.

2. ASAE. (2001) ASAE Standards. D243.3: Thermal Properties of Grain and Grain Products. ASAE, St. Joseph, MI.

3. Attah LE, Oden MI, Ibok UJ (2001). Brick forming properties of Odukpani clay deposits from physical, mechanical and mineralogical studies. West Afr. J. Res. Develop. Educ. 8(1): 93-98.2

4. Carslaw, H.S. and J.C. Jeager, (1959). Conduction of Heat in Solids Clorendon Press, Oxford. page 510.

5. Christensen T. H. (1984). Cadmium soil sorption at low concentrations: I. Effect of time, cadmium load, $\mathrm{pH}$ and calcium. Water Air Soil Pollut. 21(1-4):105-114. doi: 10.1007/BF00163616.

6. Ekpose S.D, Akpabio C.T. (1994). comparison of thermal properties of soil ample forpassively cooled building desgn[J]. Tr. J.of Physics.18:117-122.

7. Emofurieta, W.O., Ogundimu, T.O., and Imeokparia, E.G.(1994). "Mineralogical, Geological and Economic Appraisal of Some Clay and Shale Deposits in Southwestern and Northeastern Nigeria". Journal of Mining and Geology. 30(2):151 - 159 .

8. Gerriste R.G, van Driel W. (1984). The relationship between adsorption of trace metals, organic matter, and $\mathrm{pH}$ in temperate soils. J Environ Qual.13: Pages197-204.

9. Ghuman, B.S. and Lal, R. (1985). "Thermal Conductivity, Thermal Diffusivity and Thermal Capacity of some Nigerian Soils". Soil Sci. Journal. 139: $74-80$.

10. Harter R.D. (1979). Adsorption of copper and lead by AP and B2 horizons of several northeastern United States soils. Soil Sci Soc Am J.43: Pages 679683.

11. Harter R. D. (1983). Effect of soil pH on adsorption of lead, copper, zinc and nickel. Soil Sci Soc Am J.47: Pages 4751.

12. Korte N.E, Skopp J, Fuller W.H, Niebla E.E, Alesii B.A. (1976). Trace element movement in soils: influence of soil physical and chemical properties. Soil Sci.122:350-359.

13. Kotoky P, Bezbaruah D, Baruah J, Borah G, Sarma J.(2006). Characterization of clay minerals in the Brahmaputra river sediments, Assam, India. Current Sci. 91(9): 1247 -1250.

14. Murray H (1980). Major kaolin processing development, Int. J. Min. Processes 1(1): 263-274.

15. Murray HH (1963). Industrial Applications of Kaolin Clays and Clay Minerals, (Pergamon Press, London).

16. Oden M.I, Attah LE, Murray HH (2001). Clay deposits of Southern Cross River State: Mineralogy, chemical and physical properties A paper presented at the 24th Annual Internal conference of the chemical society of Nigeria (CSN) Abuja. 1: 1-15.

17. Polley S I; Synder O P; Kotnour F. (1980). A compilation of thermal properties of foods. Food Technology, 34(11),76-78.

18. Shabbir, G., Maqsood, A., and Majid, C.A. (2000). "Thermo Physical Properties of Consolidated Porous Rocks". J. Phys. 33:658 - 661.

19. Soldatini G.F, Riffaldi R, Levi-Minzi R. (1976). Lead adsorption by soils. Water Air Soil Pollut. 6(1):111-118. doi: 10.1007/BF00158719.

20. Umar M.A. and Ejila J.N. (1999).A comparative analytical study of Kaolin rocks from kankarra (Katsina State), Darazo (Bauchi state) and Mararaban rido (Kaduna State) for industrial 
application.s Nigerian Journal of mining and geology. 2(1): 23.

21. Usowicz B. (1993). A method for the estimation of thermal properties of soil. In Agrophys.7(1):27-34.

22. Worall WE (1975). Clay and Ceramic Raw Materials, (Applied Sciences Publications, London).
23. Zerroug A. and Zeehur K. (2007).Thermal conductivity models of porous materials. Journal of Eng. Appl. Sci. Vol.2 Page 722-727.

24. Zimdahl R.L, Skogerboe R.K. (1977). Behaviour of lead in soil. Environ Sci Technol.11 (13):1202-1207. doi: 10.1021/es60136a004. 